\title{
A Contrastive Study of Hard Times and the Two Versions from the Perspective of Textual Cohesion
}

\author{
Meng Yan \\ Shanxi Normal University, China
}

\begin{abstract}
Cohesion is the semantic concept of discourse. And the key to coherence of discourse is to use various cohesive devices rationally. Due to the different ways of thinking between China and the West, English and Chinese have great difficulties in textual cohesion. In order to better carry out translation practice, it is necessary to understand the cohesive devices of the text. Both English and Chinese use cohesive devices, but they are different. The complicated work of English-Chinese translation is the treatment of cohesive devices and the quality of the translation depends on the proper handling of the cohesive devices. This paper is based on a book cohesion in English by Halliday and Hasan in 1976, whose research methods are comparative analysis and descriptions. Choosing the works hard times of Charles Dickens, a famous British critic of the 19th century as well as Foreign Language Teaching and Research Press Mu Run and China Books Publishing House Wu Sujun two versions as the research object. By analyzing the differences between English and Chinese texts, the author tries to find out the reasons for the differences and hopes to provide some help for English-Chinese translation.
\end{abstract}

Index Terms-Hard Times, discourse, cohesion, Comparative study of English and Chinese

\section{INTRODUCTION}

The rise of text linguistics has made more and more theorists realize the importance of discourse. As the most basic unit of communication, in order to achieve more effective communication, the text must be clear, and at this time whether the use of cohesion and continuous means is very important. The cultivation of textual cohesion awareness can help translators understand the full text more comprehensively and improve the quality of translation. Both English and Chinese texts often use a large number of cohesive paragraphs, but because of the great differences in culture and thinking between the two languages, the use of cohesive devices in English and Chinese texts is not the same. Therefore, in translation, the translator needs to use cohesive devices reasonably so that the wording of the target text is appropriate and the meaning is clear. In 1968, Hassan first mentioned cohesion as a term in his book grammatical cohesion in spoken and written English. In the book, he mentions: we need a term to refer to a single instance of cohesion, a term that appears only for two closely connected sentences, and we call it "tie."Since its first publication in 1976, Cohesion in English has established itself as a standard textbook, which written by co-authored Halliday and Hassan in 1976, marks the establishment of cohesion theory. In cohesion in English, Halliday and Hasan clearly define cohesion as the meaning relationship in which cohesion exists within the text and makes it a text, and those non-structural, textual meaning relation. ${ }^{[1]}$.And they put forward the Register cohesion Theory which holds that discourse coherence includes two aspects: on the one hand, coherence with positional context, which is manifested as register consistency; on the other hand, discourse itself is coherent, so it is cohesive. Cohesion Theory has been further developed after it was introduced into China. Hu Zhuanglin, as one of the pioneers in the study of discourse, puts forward: "cohesion is achieved through the relationship between the surface form of language and its statements, but coherence refers to the cohesion between communicative behaviors. ${ }^{[2]} \mathrm{He}$ put forward the concept of multilevel cohesion theory and expanded the scope of cohesion. Zhang Delu and Liu Rushan also put forward a comprehensive theoretical framework from some novel angles: Positional context also has cohesive function. Therefore, it can be said that cohesive devices are an important part of discourse coherence.

Cohesion is one of the structures of composition and textual function. And the comparison of cohesive devices belongs to an important category of textual contrast. Although the cohesion among sentences belongs to the problem of discourse surface structure, that is, the structure of language form, the study in this area can reveal the unique nature of different languages, so the contrastive study of language surface structure is essential. Charles, a famous British critical realist in the nineteenth century, is selected in this paper. Dickens' work Hard Times and two English translations of Wu Sujun by China Book Publishing House and Mu run by Foreign language Teaching and Research Press are taken as the

\footnotetext{
${ }^{[1]}$ Brown, G, \&Yule, G, (1976).Discourse Analysis. Cambridge: Cambridge University Press, 127

${ }^{[2]}$ Halliday, M.A.K.\& Hasan, (1976)Cohesion in English[M]. London: Longman, 1-2.
} 
research objects. By comparing the English and Chinese languages and the cohesion at the textual level of the two versions, this paper finds out the similarities and differences and analyzes the reasons for the differences, so as to provide the target language readers with a reasonable, smooth and natural translation to reproduce the original style.

\section{A Contrastive Analysis of the Hard Times And the Chinese Version From the Perspective OF CohEsion}

Textual cohesion is an important means to achieve textual coherence, and the construction of a coherent text by means of textual cohesion is the main purpose of English writing, and the meaning of the text is inferred from the textual cohesive devices. Understanding the overall effect of text Reading is the goal of text Reading. According to Halliday and Hasan, textual cohesive devices are mainly divided into grammatical cohesive devices (including reference, ellipsis, connection and substitution) and lexical cohesive devices. Grammatical cohesion mainly includes reference, substitution, ellipsis, connection and so on. It is one of the important means to construct discourse and achieve semantic coherence.This chapter analyzes the differences between English and Chinese in terms of grammatical and lexical cohesion pairs.

\section{A. Theme of Hard Times}

Hard Times (1854) is a masterpiece of Charles Dickens, a famous British critical realist writer in the 19th century. The novel depicts the profiteering of the bourgeoisie, the poverty and suffering of the masses of workers as well as the contradictions and struggles between labor and capital which reflect the class relations and social outlook of Britain in the 1850s and make a more profound exposure and criticism of the bourgeoisie. Gradi hard, the protagonist, is a retired hardware businessman and a utilitarian belief. whether he educates his children or holds social education, he makes people believe in the "facts" and regards life as a kind of "cash transaction across the counter." Under his education, his daughter Louisa was forced to marry a capitalist thirty years older than her, Bounderby, who was mentally tortured after marriage; his son Tom gambled and fled overseas as a thief. Bounderby, a factory owner and banker, concocted his story and boasted that he had started from scratch in order to paralyze the workers and eventually lead to defections. Through the description of Graddish and Bounderby's two typical characters and their family experiences, the author reflects the class relations and social features of England in the 1850s, and makes a more profound exposure and criticism of the bourgeoisie.

\section{B. Differences in Cohesive Devices between Hard Times and the Chinese Version}

Although both English and Chinese cohesive devices can play the role of connecting context to transmit semantic relations in the text, there are obvious differences in the specific use of cohesive devices. This section will make a contrastive analysis of the textual differences between English and Chinese from the aspects of vocabulary, ellipsis, substitution and anaphora cohesive devices.

1. Differences in lexical cohesion between English and Chinese

Lexical cohesion refers to the realization of textual cohesion and semantic coherence through the relationship between repetition and co-occurrence of words. Lexical cohesion is another form of cohesive devices, which divides lexical cohesion into co-occurrence relationship and repetition relationship. Co-occurrence relationships include antonyms, lower words and word collocations, and repetition relationships include repetition, synonyms, synonyms and upper words.

Eg1: Such a woman! A poor, drunken thing. Hardly able to sit up. Dirty, untidy hair covered her purple face.

$\mathrm{Mu}$ Run's version:一个可怜的醉鬼，几乎无力坐起身来，肮脏零乱的头发披在她发紫的脸上。（ Mu Run,1995,p97)

Wu Sujun's version: 这是一个什么样的女人呢? 一个穷困潦倒、醉醺醺的废物, 甚至连站都站不起了。她衣衫 褴褛那脏兮兮、乱蓬蓬的头发遮住了她发紫的脸。Wu Sujun2006,p,53)

In the example sentence, "thing" is translated as“醉鬼” “废物”, which means the general term for describing all the bad state of the woman after she is drunk; "dirty" untidy "is repeated in the example sentence using the inflection form in English. The sentences are connected from the text level, while the Chinese is gathered in form and mind, combined with context and association. The choice of words and sentences in a text is a chain that runs through the full text. When translating, it is necessary to understand the meaning and usage of the words, and to convey the author's intention through words as much as possible while maintaining the semantic coherence of the full text.

2. Differences in ellipsis reference between English and Chinese.

Ellipsis is to avoid repetition, highlight new sentences and thus save some components . English and Chinese have different structures, and their ellipsis is also different. Ellipsis refers to the omission of one or more elements of a text.

Its function is similar to that of substitution, but also in order to avoid repetition, make the expression concise and clear, and at the same time make the context of the text compact and coherent.

$\mathrm{Eg} 2$ : so there is some difference in your ages. But from the point of view of social position there is no differences. Love does not come into the question.

$\mathrm{Mu}$ Run's version: 在年龄上是有些差距，但从社会地位的观点看却没有差距，爱情跟这没有关系。（Mu Run,1995,p79) 
Wu Sujun's version: : 年龄上是有些不相称, 但在社会地位上是平等的, 爱情不是一个问题。 $(\mathrm{Wu}$ Sujun2006,p,113)

In example 2, it is obvious that the English sentence has a corresponding subject "there, love". However, in the Chinese article, a series of sentences without a subject omit the subject "you". Grammar and logicality are often considered in English. The subject can not be omitted otherwise the sentence is incomplete, but the Chinese parataxis language can achieve meaning in ellipsis without considering the grammatical structure.

3. Differences in substitution between English and Chinese.

The substitute word only replaces a certain component in form, and its meaning also needs to be found in the relevant context. Substitution refers to the replacement of a component with an alternative word. Alternative words are only forms, and their semantics should be found from the components they replace. On the one hand, its function is to avoid repetition and make the expression concise, compact and clear. on the other hand, it is to connect the context and make the meaning coherent.

Eg3: Your word is law to me. Yes, and a good, bright law. Better than some of the real ones.

Mu Run's version: 你的话就是我的法律。对, 光明而美好的法律。比有些真的法律还好。（Mu Run,1995,p53）

Wu Sujun's version: 你的话就是我的法律。是的, 多么欢快的、美好的法律啊！比那些真的法律要强的多了。

(Wu Sujun, 2006, p, 75)

In this example, it can be seen that "ones" replaces 法律 in the text, but there is no such corresponding word in Chinese to replace 法律.For substitution, Chinese often uses the way of reproducing the original words to form the cohesion to the following text. If there is no substitute, the translation repeats the same elements.After the substitution, the text becomes concise and more in line with the Chinese expression.

4. Differences in connection between English and Chinese.

Connectives often play an excessive role in causality, time and so on. because of the different ways of thinking between China and the West, English and Chinese are not the same in connection translation. In a sentence, among clauses, there are usually connective elements to connect them, indicating the logical semantic relationship and interdependence between clauses. This connection usually runs through the full text. ${ }^{[1]}$

Eg4: Whenever things are bad, i will try to think of you, and look forward to a time when you and $i$ can walk together in peace and happiness.

Mu Run's version:无论什么事情再糟, 我都会尽力想到你。希望有一天, 我们俩能平平安安、幸福快乐地走在 一起。（Mu Run,1995,p73）

Wu Sujun's version: 无论何时碰到任何坏事, 我都会试着想想你, 盼着有朝一日你和我可以平静幸福地走在一 起。(Wu Sujun2006,p,101)

In the example sentence, the three conjunctions "whenever", "and" when "clearly show that the semantic relations between English sentences appear by conjunctions, while the understanding of sentences in Chinese depends on logical relations and their order of invisibility.

5. Differences in reference between English and Chinese.

Reference is the understanding of a word that can be expressed by the object referred to in the context. In a text, if the interpretation of a word cannot be obtained from the word itself, but must be answered from the object to which the word refers, this gives rise to a reference relationship. In this reference relationship, one component acts as the reference point of another component, that is, the relationship between one language component and another component that can be explained to each other.

Eg5: "Fancy," said the gentleman, "You must not do that. You must stick to the facts, and forget the word Fancy.

Wu Sujun's version: “幻想, ”那位绅士说, “你绝不可那样的。你必须忠于事实, 忘了“幻想”这个词儿吧。你 不能和它沾上边。(Wu Sujun2006, p, 10)

Mu Run’s version: “想象!”那位绅士叫了起来, “你不能那样做, 你不能坚持事实, 忘记想象。(Mu Run,1995,p6)

In this sentence, the definite article the appears three times, especially for a specific person or thing in the text; in Chinese, it is not.

\section{The Characteristics of the Translator's Choice of Cohesion in Dealing With the Original TeXt}

The translator's style is not the same. This chapter makes a contrastive analysis of the reasons for the different styles of the two Chinese versions and the two translators in dealing with the original text from the perspective of textual cohesion.

\section{A. A Contrastive Analysis of Textual Cohesion in Two Chinese Versions of Hard Times}

Eg6: I am so proud and so hardened, so confused and troubled, so full of hate that everything seems dark and stormy to me. Doesn't that frighten you?

Mu Run's version:我铁石心肠, 现在的处境有很困难。在我心中充满了仇恨, 一切对我来说都是黑暗无边。这 些不让你害怕吗?（Mu Run,1995,p171）

Wu Sujun's version: 我是如此傲慢, 如此冷酷, 而且心绪紊乱, 痛苦不堪, 对一切都充满了厌恶, 任何事物 


\section{对我来说都是黑暗和粗暴。对这样的我，你不害怕吗？(Wu Sujun2006, p, 243)}

In example 6, the translation of the wooden version of "铁石心肠, 现在的处境有很困难" is more general, translated as "hard heart, the present situation is very difficult," while Wu Sujun's version tends to translate literally. Reproduce the original text in a clear, shallow, vivid language translated as "傲慢, 如此冷酷, 而且心绪紊乱, 痛苦不堪"

Eg7: When he rose to return to his hotel for the night, the whelp immediately offered his services as guide.

Mu Run's version:当哈特豪斯动身去旅馆过夜时，小狗立刻自告奋勇为他领路。(Mu Run, 1995, p101)

Wu Sujun's version: 晚上他起身回旅馆时, 那个小兔思子便立即自告奋勇地要当向导。(Wu Sujun2006, p,151)

In example 7, Mu run and Wu Sujun take two different approaches to the translation of the same character. the original the whelp originally refers to the protagonist's son Tom. Because of the retribution for strict tutoring, Tom became a dissolute, hedonistic and hypocritical young man, but very much loved by his sister. Mulun's version, translated as "puppy", uses irony to highlight the character's character, while Wu Sujun uses "little son of a bitch" as a nickname to explain the character from the sister's point of view.

\section{B. Reasons for Translators' Different Styles}

The translator's style is influenced by many factors, including the translator's sociocultural background, translation purpose, target readers, and his translation theories or viewpoints. It is not easy to convey a writer's style "authentic"! Because of the differences between the two languages, especially between the East and the West, it can be asserted that it is almost impossible to express the style of a writer $100 \%$. Since the translator has his own writing style, it is difficult for him to overcome his own writing style and use another writing style to translate the works of another writer when translating the works of different writers. What we often see is that the same translator always uses the same tone when translating the works of different writers. From the study of cohesion theory, it is found that Mu run's version and Wu SuJun's version are different in the way of cohesion, The language style of Mu Run translation is close to that of the target reader, the vocabulary is rich, the sentences are authentic, and the amount of text also accords with the translation principle. The overall colloquial features of the translation are obvious and readable. Mu run not only takes into account the subjective position of the reader, but also faithful to the original text, and strives to maintain the characteristics of the original text. Wu SuJun's translation tends to be more flexible in cohesive devices under the influence of the target language, and the $\mathrm{Wu}$ SuJun version is more influenced by the original language system and faithful to the original. Wu Sujun's version to a large extent retains the characteristics of concise whitening of the source text; on the basis of highly retaining the characteristics of the original text, it is more inclined to save the translation of the whole sentence than to add the whole sentence. Therefore, his translation style presents the characteristics of concise, simple and clear words and sentences. From the age, it can be seen that Mu run was earlier than Wu Sujun, they received different cultural and linguistic backgrounds, and their translation strategies were different. In a word, both the Mulun version and the Wu Sujun version provide cultural transformation in English-Chinese translation.

\section{CONCLUSION.}

Due to the different ways of thinking between China and the West, English and Chinese have great difficulties in textual cohesion. In order to better carry out translation practice, it is necessary to understand the cohesive devices of the text.There are similarities and differences between English and Chinese textual cohesion. As Halliday and Hasan

${ }^{[1]}$ say, "the fundamental difference between a text and a non-text lies in whether it is textual, and textual is the formation of cohesive relations" Discourse is coherent, and textual cohesion is an important means to achieve textual coherence. The study of the characteristics and functions of textual cohesion is of great significance to English learning and its application. on the one hand, it can help English learners to identify textual cohesive devices and understand the author's true intention. On the other hand, it can help learners to construct coherent texts, accurately express their own ideas, and achieve successful communication with readers. Cohesive devices play an important role in semantic coherence and logical relations. From the contrastive analysis of English and Chinese, it can be seen that English is more likely to reproduce, refer to and replace the original words of lexical cohesion than Chinese, while Chinese mostly uses ellipsis. Compared with the Chinese version, it can be seen that the translator's age is affected by social environment factors, and the translated text is also very different. Combined with the cohesive coherence theory of Halliday and Hasan, this paper analyzes the sentences containing cohesive devices in the book from three angles: reference, substitution and ellipsis, and connection. The translation strategies of cohesive devices in English-Chinese translation are briefly summarized. Through translation practice and analysis, the author finds that English emphasizes hypotaxis, grammatical structure is rigorous, grammatical means are often used to form cohesion, while Chinese emphasizes parataxis, and the treatment of cohesive devices is more flexible. In the process of translation, translators mainly use the following three means: ellipsis, repetition, adjustment of wording and word order. Ellipsis can be used in personal reference, supplementary connection, turning connection, causal connection, clause ellipsis translation repetition can be used in personal reference, noun substitution, and ellipsis cohesion translation; The method of adjusting wording and word order can be used to compare the translation of reference, transition connection, causal connection and patio-temporal connection. However, these methods are not absolute, but also need to make a specific analysis according to the context. The cohesive devices discussed in this paper are based on the theory put forward by 
Halliday and Hasan and are limited to the surface structure of the text, but the scope of cohesion is much larger than that proposed by Halliday and Hasan. Based on the contrastive analysis of the characteristics and differences of textual cohesion between English and Chinese, combined with concrete examples, this paper seeks effective strategies in translation so that translators can draw lessons from them and go further in translation.

\section{REFERENCES}

[1] Brown, G, \&Yule, G. (1976). Discourse Analysis. Cambridge: Cambridge University Press, 127

[2] Dickens, Charles. (1995). Hard Times. Translated by Mu Run. Beijing: Foreign language Teaching and Research Press.

[3] Dickens, Charles. (2006). Hard Times. Translated by Wu Sujun. Beijing: China Book Publishing House.

[4] Halliday, M.A.K.\&Hasan. (1976). Cohesion in English. London: Longman, 1-2.

[5] Huang Guowen. (1998).Theory and practice of discourse Analysis. Shanghai: Shanghai Foreign language Education Press.

[6] Hodges B D, Kuper A, Reeves S. (2008). Discourse analysis. London: British Medical Journal, 337:a879.

[7] Hoey, Michael. (1991). Patterns of Lexis in Text. Oxford: Oxford University Press.

[8] Van Dijk, T.A. (1977). Text and Context: Explorations in the Pragmatics of Discourse. London \& New York: Longman.

[9] Widdowson H G. (1984). Explorations in applied linguistics. Oxford: Oxford University Press, 1984.

[10] Zhang Delu, Liu Rushan. (2003). The Development and Application of discourse coherence and cohesion Theory. Shanghai: Shanghai Foreign language Education Press.

Meng Yan was born in Hubei, China in1994. She was admitted to Shanxi Normal University in 2017, majoring in linguistics and applied linguistics. And now she's a second-year undergraduate. The direction she is interested in is translation and pragmatics. 